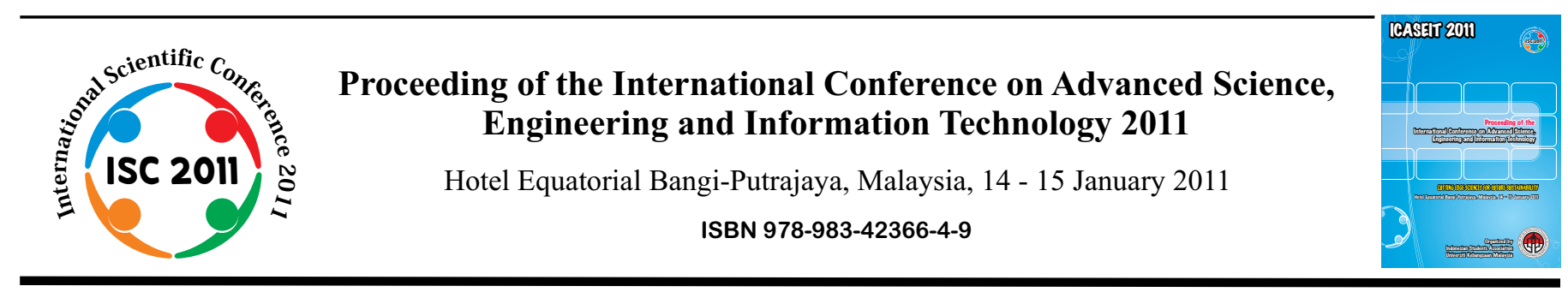

\title{
User Interface Design, Standards \& Guidelines for Web Applications Based on Human Personality Types
}

\author{
Kasthuri a/p Subaramaniam ${ }^{1}$, Oras F. Baker ${ }^{2}$, Nael Kabbany ${ }^{3}$ \\ Faculty of Management\& Information Technology, UCSI University \\ Kuala Lumpur, Malaysia \\ ${ }^{1}$ kasthurisuba@ucsi.edu.my \\ 2orasbaker@ucsi.edu.my \\ 3naelk@ucsi.edu.my
}

\begin{abstract}
This paper discusses the standards and guidelines of user interface features in web-based applications for the different personality types of people. An overview of human computer interaction and human personality types is described. LEONARD, Let's Explore our personality type based on Openness $(O)$, Neutral $(N)$, Analytical $(A)$, Relational $(R)$ and Decisive $(D)$ is the model used to determine the different personality types for this study. The purpose is to define user personality profiles and to establish guidelines for the graphical user interface. The personality inventory and a user interface questionnaire were administered to university students. Interview sessions were also conducted and parts of the interviews with the university students were used to validate the results obtained from the questionnaires. The analysis of the students' personality types identified five main groups. The results suggest that users do have definable expectations concerning the features of web applications. This profile served as basis for the guidelines of web features for the graphical user interface design for the particular user groups.
\end{abstract}

Keywords - human personality types, user profiling, user interface, web applications, web-design guidelines

\section{INTRODUCTION}

HCI is the study of the interaction between people, computer and tasks. It is principally concerned with understanding how people and computers can interactively carry out tasks, and how such interactive systems are designed [1]. Arriving at a thorough understanding of the users and their tasks is crucial to any system development process. Systems can be designed simpler, yet custom tailored to specific needs by studying the moods, behaviors and motivations of users [2]. Users seem to behave differently in different situations regardless of their membership to a group because users behave unpredictably and their behavior is largely based on situational moods [3].

The purpose of this study was to establish a set of guidelines and principles that can be easily applied by user interface designers as most of them do not consider interfaces as part of the system and worse, the user is rarely considered [4]. This study defines guidelines for the overall design of a general web-based application for the five user groups of $\mathrm{O}, \mathrm{N}, \mathrm{A}, \mathrm{R}$, and NA that would be adapted to the users' needs. The principles and guidelines were intended for users to accomplish tasks more quickly and efficiently.

\section{Methodology}

The user interface design guidelines are based on requirements gathered through questionnaires and interviews. Two methods of the information gathering process for this study were conducted at a university. The Leonard Personality Inventory (personality test) was given together with the User Interface Questionnaire.

\section{A. Leonard Personality Inventory (LPI)}

The Leonard Personality Inventory is a self report personality inventory designed to provide information about 
a person's personality type. Leonard M.S. Yong developed the LPI [5]. Leonard results indicate the respondent's likely preferences on five main dimensions:

$\begin{array}{ll}\text { Openess } & \text { (O) } \\ \text { Neutral } & (\mathrm{N}) \\ \text { Analytical } & (\mathrm{A}) \\ \text { Rational } & (\mathrm{R}) \\ \text { Decisive } & \text { (D) }\end{array}$

Results on the indicator are generally reported with letters representing each of the preferences as indicated above. There are 16 possible ways to combine the preferences, resulting in the following 16 LEONARD types: High $O$, High N, High A, High R, High D, High N\&D, High A\&R, High R\&D, High N\&A, High N\&R, High O\&R, High A\&O, High $O \& N$, High $O \& D$, High A\&D\&O and High $O \&$ combination of any other three dimensions. It must be stressed that all types are good, normal, and none is superior to the others regardless of their strengths and weaknesses [6].

\section{B. User Interface Questionnaire (UIQ)}

The User Interface Questionnaire was designed to gather information on the preferences of user interface features and to assess users' subjective satisfaction with specific aspects of a general web interface.

\section{Interviewing Process}

Interviews were conducted at a university to get feedback on the features that were preferable for a web interface design. A structured format was used for the interviews, which included standard demographic information and level of experience with the Internet.

\section{FINDINGS AND RECOMMENDATIONS FOR USER INTERFACE DESIGN}

D. Findings from the Personality Instrument of Respondents

The results of the questionnaire are shown in Figure I. It was discovered that of the 635 respondents, 72 respondents scored in the "O" type, 90 in the " $\mathrm{N}$ " type, 56 in the " $\mathrm{A}$ " type, 50 in the "R" type and 35 in the "N\&A" type. 147 respondents scored in the "Others" type which include types $\mathrm{D}, \mathrm{ND}, \mathrm{AR}, \mathrm{RD}, \mathrm{NR}, \mathrm{OR}, \mathrm{AO}, \mathrm{ON}, \mathrm{OD}, \mathrm{ADO}$ and a combination of any other three dimensions.

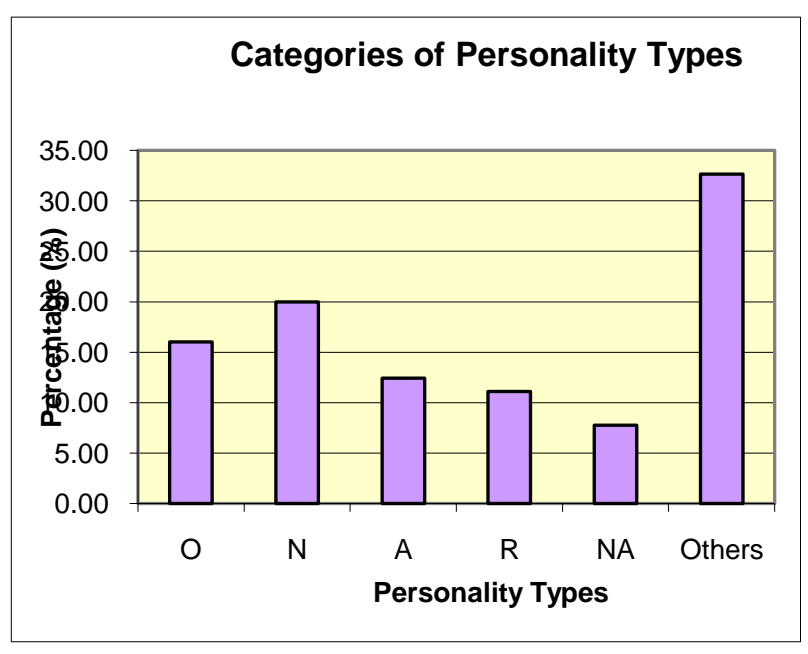

FIGURE I: Categories of Personality Types

To allow for concrete comparison of the potential of this personality inventory, the short versions of the descriptions are included below. The proposed recommendations for the user interface design for web-based application are attempts to translate general statements of the respondents' personalities.

\section{E. Description of Personality Types}

The O type

$O$ types are adaptable and flexible with creative and strong imaginations. However, they tend to get bored easily and are very inquisitive. Thus, they find others' ideas too shallow and unimaginative.

\section{The $\mathrm{N}$ type}

Neutral types are supportive and accept others' suggestions and ideas. In view of that, they tend to compromise so as to avoid conflicts but they lack in confidence. They require a friendly atmosphere to work best and shrink from difficult situations.

\section{The A type}

Analytical types prefer to have established procedures to follow whereby the information has to be put down in black $\&$ white. However, they are rather slow to respond to new ideas. Thus, they are inflexible.

\section{The R type}

$\mathrm{R}$ types are spontaneous and enthusiastic but they are restless and disorganized.

\section{The D type}

D types love challenges and desire to be in control. However, they do get easily irritated and are quite impatient.

F. Recommendations for User Interface Design of the Different Personality Types

As the $\mathrm{O}$ types are adaptable and flexible, they prefer text/word to be highlighted. The terminology used on a web page must be consistent and headers are to be placed on each 
web page. However, selecting items from a drop-down list, or having links in a web page or even having text blinking are not favored features as they tend to get bored and find them awkward.

Since the $\mathrm{N}$ types shrink from difficult situations, making changes or having abbreviated words in a web page is not appreciated at all.

The A types are very concrete in their work style. Therefore, searching for information must be very straightforward, terminology used must be consistent and fancy design is not appreciated. Furthermore, they tend to avoid making changes, having images to describe about the contents or having abbreviated and mnemonics used in a web page.

The $\mathrm{R}$ types do not prefer objects or animations moving around, mnemonics and abbreviated words as they tend to get restless. However, they are spontaneous in making changes on a web page.

The NA type is particular about having things done the right way. This group does things by the book and follow established rules. However, having minimal manuals, animations and moving objects in a web page are not acceptable.

\section{PRINCIPLES AND GUIDELINES FOR USER INTERFACE DESIGN OF THE DIFFERENT PERSONALITY TYPES}

The following principles and guidelines were concluded for the design of user interface for the different personality types:

\section{The O, N, A, R, and NA types:}

Avoid unnecessary text/word blinking.

Have meaningful headers to convey information.

Use consistent terminology throughout the web page.

Similar functions grouped together to maintain consistency.

Limit user decision making. Provide the user with the information necessary to form decisions quickly and accurately such as providing online help.

Use concise wording as screens have limited space.

Use appropriate abbreviations.

Use friendly instead of "harsh" terms when errors are made. Therefore, error messages should communicate with respect. Preferably in color.

Avoid advertisements and moving objects on a web page.

The O, N, R, and NA types:

Highlight important information by using color.

Have real world looks of an interface by using metaphor.

All icons placed within a web page.

Prefer graphical buttons to standard buttons.

Have minimal manuals on a web page.

Have images to describe about the contents.
The N, R and NA types:

Help the user navigate by providing navigation components such as selecting items from a drop down list or menus.

The $\mathrm{O}$ and NA types:

Prefer abbreviated words.

Prefer mnemonics to be used.

The LEONARD describes sixteen main possible types such as shown in Table I.

TABLE I

Description of Leonard Personality Types

\begin{tabular}{|l|l|}
\hline \multicolumn{2}{|c|}{ LEONARD PERSONALITY TYPES } \\
\hline High Openness (O) & Creative Imaginator \\
\hline High Neutral (N) & Neutral Expert \\
\hline High Analytical (A) & Scientific Thinker \\
\hline High Relational (R) & Relational Interactor \\
\hline High Decisive (D) & Decisive Decision Maker \\
\hline High Neutral \& Decisive (ND) & Accomplisher \\
\hline High Analytical \& Relational (AR) & Assessor \\
\hline High Relational \& Decisive (RD) & Exhorter \\
\hline High Neutral \& Analytical (NA) & Error-Buster \\
\hline High Neutral \& Relational (NR) & Encourager \\
\hline High Openness \& Relational (OR) & Creative Relator \\
\hline High Analytical \& Openness (AO) & Creative Thinker \\
\hline High Openness \& Neutral (ON) & Creative Expert \\
\hline High Openness \& Decisive (OD) & Creative Decision Maker \\
\hline High Analytical \& Decisive \& & Innovator \\
\hline
\end{tabular}

\section{CONCLUSION}

Personality assessment can be used in the design process of web applications to define user personality profiles and to 
identify crucial user interface elements. The interviews confirmed some of the findings from the instrument. A good user interface which follows the principles and guidelines makes an application easy, practical, and efficient to use. It has to be understood that the marketplace success of today's software programs depends on good interface design. Therefore, carefully designed layout will help users orient themselves, locate information, and navigate efficiently and effectively. Use of these principles governs the amount of information to present, the proper way to group this information, and the proper placement and sequencing of this information on the screen. Therefore, unnecessary details should be avoided. Our goal here is not to provide measurable standards, but rather to encourage better design and improve usability. A reasonable interface should be given to users as they only want to get their jobs done in an effective manner. It is best hoped that the personality profiles might be able to provide some information to design a better user interface that meets the needs of the different types of users. In short, the LPI achieved its purpose and provided helpful information to develop guidelines for the interface design.

\section{REFERENCES}

[1] Alan Dix, Janet Finlay, Gregory Abowd \& Russell Beale, Human Computer Interaction, 2nd Edition, Prentice Hall, New Jersey, 1998.

[2] Robert Fuchs, "Personality Traits: The Missing Piece to Develop Design Guidelines for Graphical User Interfaces", Proceedings of OZCHI, 2001, pp. 38-44.

[3] Rozanski, H.D., Bollman G. \& Lipman M., "Sieze the Occasion: Usage-based Segmentation for Internet Marketers", eInsights, Booz-Allen \& Hamilton, 2001.

[4] A. F. Norcio. "The Software Engineering of Adaptive HumanComputer Interfaces", IEEE International Conference on Systems, Man and Cybernetics, 1989, pp. 886-888.

[5] M. S. Yong, Leonard, The Leonard Personality Inventory, Petaling Jaya, Malaysia, 1999.

[6] P. Rosati., "Student Retention from First-year Engineering Related to Personality Type", Proceedings of the Twenty-Third Annual Conference of Engineering Education: Renewing America's Technology, 1993, pp. 37-39. 